\title{
FEASIBILITY OF A CASE-BASED EDUCATIONAL INTERVENTION FOCUSING ON PREVENTION OF BLOOD AND BODY FLUID EXPOSURE AMONG NURSING STUDENTS
}

\author{
Mai Thi Lan Anh'1, Dao Trong Quan², Hoang Thi Minh Thai', \\ Nguyen Manh Dung ${ }^{1}$, Vo Thi Thu Huong ${ }^{1}$, Do Thi Hanh ${ }^{1}$ \\ ${ }^{1}$ Nam Dinh University of Nursing; ${ }^{2}$ Thai Nguyen University of Medicine and Pharmacy
}

\begin{abstract}
Purpose: There was a relative lack of research regarding case-based educational interventions to improve blood and body fluid exposure prevention practice among nursing students. This study aims to develop and test the feasibility of a case-based educational intervention program and its effects with the expectation of improving students' knowledge, attitude and practice of preventing blood and body fluid exposure at Nam Dinh University of Nursing. Method: This study employed a one-group pre-posttest design. Convenience sampling was used to recruit through the target population to obtain 35 nursing students. Students' blood and body fluid exposure prevention knowledge questionnaire and Students' self-reported exposure prevention behavior scale were used to collect data at three-time points. The case-based educational intervention was adapted from the intervention program by Thai et al. and intensively reviewed relevant literature about educational intervention studies in the prevention of fluid and blood exposure. Results: The findings revealed that the participants were recruited smoothly and attended completed intervention sessions with positive feedback. We found significant positive changes in students' knowledge, attitude and practice of preventing blood and body fluid exposure after receiving the intervention. Conclusion: The results provide evidence that the case-based educational intervention was feasible and of benefit to nursing students.
\end{abstract}

Keywords: Case-based education, prevention, blood and body fluid exposure, nursing students

\section{INTRODUCTION}

The clinical environment at the hospital always contains potential occupational risk factors. Which, exposure to infectious diseases through blood or body fluids is a common problem and causes many serious consequences for health care workers. The study results indicated that nursing students were injured by needles/sharp objects and exposed to blood or body fluids [1-4]. The consequences of exposure to blood and body fluids increase the risk of anxiety and stress among students, more seriously the risk of infection with blood-borne pathogens and life-threatening [5]. $17.8 \%$ of students experienced occupational exposure during their clinical internship. Factors that
Cor. author: Mai Thi Lan Anh

Address: Nam Dinh University of Nursing

Email: lananh.ndun@gmail.com
Received: Feb 08, 2022

Accepted: Mar 06, 2022

Published: Mar 07, 2022 
contribute to student exposure risks such as lack of experience, skill, or knowledge of how to handle healthcare equipment; worry; tiredness; lack of professional support [5-8].

Study results indicated that the effectiveness of education and training for students effectively limited the risks of occupational exposure for nursing students there were various educational interventions to improve blood and body fluid exposure prevention practice among nursing students [9-14]. The research mentioned that case-based educational intervention was associated with increased knowledge, compliance, and practical quality and outcomes in patients [8]. The case-based educational intervention about blood and body fluid exposure prevention presented their effectiveness for nursing students, these programs should be offered repeatedly during clinical practice to reinforce students' knowledge and adherence to blood and body fluid exposure prevention practice [9-10]. In addition, the technology-based educational interventions with focus group discussions and peer-assisted learning can help strengthen the practice of blood and body fluid exposure prevention in safe clinical practice. Traditional educational methods using video presentations, demonstrations, and structured observations proved that nursing students received adequate support in solving blood and body fluid exposure prevention issues encountered during clinical practice [11-13]. Among the interventions mentioned, the case-based educational intervention exhibited certain strengths in improving students' knowledge and strengthening safe practices for the prevention of blood and fluid exposure.

There was a relative lack of research regarding case-based educational interventions to improve blood and body fluid exposure prevention practice among nursing students in Vietnam [13-14]. Therefore, this study aims to develop and test the feasibility of a case-based educational intervention program and its effects with the expectation of improving students' knowledge, attitude and practice of blood and body fluid exposure prevention at Nam Dinh University of Nursing. In addition, after conducting a feasibility study, the researcher gained more experience in performing the intervention with participants in a prospective randomized controlled trial that was replicated in several settings of universities. Finally, the researcher may adjust the data collection method to ensure the validity and reliability of the intervention program and study measurements.

\section{PARTICIPANTS AND METHODS}

This study employed a one-group preposttest design.

\subsection{Sample and sampling}

The target population was final year nursing students at Nam Dinh University of Nursing who practiced in clinical settings. Convenience sampling was used to recruit through the target population to obtain 35 nursing students. The inclusion criteria were final year students who belong to the 12th course, had studied the infection prevention and control module and achieved a grade of $D$ or higher. Exclusion criteria were that the students repeated the internship and were unable to complete all sessions of the intervention.

\subsection{Development of the case-based educational intervention}

The case-based educational intervention was adapted from the 
intervention program by Thai et al. and intensively reviewed relevant literature about educational intervention studies in the prevention of fluid and blood exposure. For the convenience of students to participate fully in the entire intervention program, the intervention protocol included four-weekly face-to-face sessions. Special attention to the case-based educational intervention program was given to problem-solving based on the designed cases and students' action plans.

The program plan included groups of 8 to 12 students over four sessions. Each session lasted 60 minutes. The content for the short presentations was based on the difficulties and challenges of students about prevention discussed earlier. Lectures were designed in the form of handouts and Powerpoint presentations.
Discussions were followed after each presentation regarding the designed cases. An individual action plan was developed at the end of each session. The content was in the student handout with a schedule of sessions; references; designed cases with suggestions on prevention and management measures in prevention of exposure to blood and body fluids; action plan and evaluation sheet at the end of the intervention program.

\section{The students' booklet}

The content of the intervention program was included in the student booklet The booklets were distributed to the students during the first session. The research team instructed students to use the booklet in the clinical setting, in the intervention sessions and in the future after finishing the intervention program.

Table 1. Summary of the case-based educational intervention

\begin{tabular}{|c|c|c|}
\hline $\begin{array}{c}\text { Week/ } \\
\text { day }\end{array}$ & Objectives & Contents \\
\hline $\begin{array}{l}\text { Week } \\
1 \text {-day } 1 \\
(60 \mathrm{~m})\end{array}$ & $\begin{array}{l}\text { Overview of case-based } \\
\text { educational intervention } \\
\text { on prevention of blood } \\
\text { and body fluid exposure }\end{array}$ & $\begin{array}{l}\text { - Welcome and Class Introduction } \\
\text { - Overview of case-based educational intervention on } \\
\text { prevention of exposure to blood fluids } \\
\text { - Cases and group discussions } \\
\text { - Action planning } \\
\text { - End of the session }\end{array}$ \\
\hline $\begin{array}{c}\text { Week } 2 \\
(60 \mathrm{~m})\end{array}$ & $\begin{array}{l}\text { Prevention for exposure } \\
\text { to blood/body fluids in } \\
\text { clinical practice }\end{array}$ & $\begin{array}{l}\text { - Feedback/problem solving on student action plans } \\
\text { - Prevention for exposure to blood/body fluids in clinical } \\
\text { practice settings } \\
\text { - Cases and group discussions } \\
\text { - Action planning } \\
\text { - End of the session }\end{array}$ \\
\hline $\begin{array}{c}\text { Week } 3 \\
(60 \mathrm{~m})\end{array}$ & $\begin{array}{l}\text { Process the initial } \\
\text { exposure steps, generate } \\
\text { exposure reports based } \\
\text { on the cases and assess } \\
\text { the risk of exposure. }\end{array}$ & $\begin{array}{l}\text { - Feedback/problem solving on student action plans } \\
\text { - Procedure for initial exposure steps } \\
\text { - Cases and group discussions to generate exposure } \\
\text { reports according to available forms and assess exposure } \\
\text { risks. } \\
\text { - Action planning } \\
\text { - End of the session }\end{array}$ \\
\hline
\end{tabular}




\begin{tabular}{|c|c|c|}
\hline $\begin{array}{c}\text { Week/ } \\
\text { day }\end{array}$ & Objectives & Contents \\
\hline $\begin{array}{c}\text { Week } 4 \\
(60 \mathrm{~m})\end{array}$ & $\begin{array}{l}\text { Review the specific } \\
\text { prophylactic measures } \\
\text { available to each case, } \\
\text { and follow-up monitor } \\
\text { and evaluation after each } \\
\text { exposure. }\end{array}$ & $\begin{array}{l}\text { - Feedback/problem solving on student action plans } \\
\text { - Post-exposure prophylaxis, monitoring and evaluation } \\
\text { measures } \\
\text { - Cases and group discussion for prophylactic measures, } \\
\text { and post-exposure monitoring and evaluation. } \\
\text { - Action planning } \\
\text { - End of the intervention program, survey immediately } \\
\text { after the intervention, evaluate the intervention program } \\
\text { and make an appointment for the survey after } 4 \text { weeks }\end{array}$ \\
\hline
\end{tabular}

2.3. Assessment of the feasibility of the case-based educational intervention

To assess the feasibility of the intervention, all aspects of the student's recruitment, intervention program attrition rate were documented. Finally, to assess the differences in knowledge, attitudes, and self-reported behaviors about prevention of blood and fluid exposure, students completed the questionnaires at three-time points, at baseline, post-intervention and follow-up.

A demographic questionnaire was developed by the primary investigator (PI) to record the following information: gender, age, a final grade of infection prevention and control course, hepatitis disease, duration of illness, HBV vaccination.

Students' blood and body fluid exposure prevention knowledge questionnaire included 10 items to assess blood and fluid exposure prevention. each correct answer was worth 1 point with a total knowledge score ranging from 0 to 10 . the higher the total score, the better the knowledge about prevention of exposure to blood and body fluids.

Students' blood and body fluid exposure prevention attitude questionnaire to assess exposure prevention attitudes was developed based on the questionnaire of Hoang Minh Thai et al (2020). The questionnaire consisted of 28 questions. The questionnaire was scored on a 5-point Likert scale showing strongly agree, agree, normal, disagree and strongly disagree. The total score ranges from 28 to 140 , calculated from the scores of all questions, the higher the score, the more positive the attitude. Thai et al., (2020) indicated that the questionnaire exhibited good reliability of 0.82 [10].

Students' self-reported exposure prevention behavior scale: The scale was developed under the $\mathrm{MOH}$ standard prevention guidelines (2012) was conducted to assess exposure prevention behavior during hospital practice on behaviors related to hand washing, glove-wearing, and needle handling. The questionnaire consisted of 5 items, scored on a 5-point Likert scale showing always, often, sometimes, rarely and never, with a total behavioral score ranging from 5 to 25 . The higher the total score, the safer the prevention of exposure to blood and body fluids. The reliability of the scale in the current study was 0.79 .

The case-based educational intervention program was evaluated for validity by 3 content experts, including 02 heads of the Infection Control Department 
and 01 hospital head nurse. The research team then revised the content in the intervention according to the comments and suggestions of experts.

\subsection{Data collection}

After obtaining the approval of the Ethics Committee, the research team approached potential students to invite them to participate in the study. If the student agrees to participate, the student may sign the consent form.

Week 1: Conduct a pre-intervention survey. The research team distributed questionnaires (before the intervention, T1). Introduction to the educational intervention program and basic knowledge of exposure to blood/body fluids.

Week 2: Prevent exposure to blood/ body fluids.

Week 3: Immediately after exposure.

Week 4: Post-exposure process. Discuss the effectiveness of educational interventions to prevent exposure to blood/ body fluids from the student's perspective. Post-intervention survey (immediately after the intervention, T2). At the end of week 4, the PI interviewed the participants to complete the questionnaire (post-test, $\mathrm{T}_{3}$ ). While conducting the pilot study, the research assistants also were trained to become familiar with instruments for data collection.

2.5. Data analysis: The collected data were cleaned, entered, processed and analyzed on SPSS 16.0 software. Descriptive statistics and paired t-tests were used to analyze the data.

\subsection{Ethical issues}

Prior to data collection, permissions were received from the institutional review board. The participants were informed about the study's purpose, data collection procedure, benefits and risks, and confidentiality of information. They had the right to participate voluntarily, withdraw during data collection and the intervention, or terminate the study without penalty. After indicating their willingness, they signed informed consents.

\section{RESULTS}

Participants' characteristics and attrition rate

Table 2. Participants' characteristics

\begin{tabular}{|lcc|}
\hline \multicolumn{1}{|c|}{ Characteristics } & $\mathbf{n}(\mathbf{3 3 )}$ & $\%$ \\
\hline $\begin{array}{l}\text { Gender } \\
\text { Male }\end{array}$ & 3 & 10.0 \\
Female & 30 & 90.0 \\
\hline Vaccination & 5 & 15.0 \\
Yes & 28 & 85.0 \\
No & & \\
\hline Infected hepatitis virus & & \\
HAV & 0 & 0.0 \\
HBV & \\
HCV & \\
HDV & \\
HEV & \\
HIV & \\
\hline $\begin{array}{l}\text { The average grade of } \\
\text { the infection prevention } \\
\text { and control course }\end{array}$ & Mean: $7.85 \pm 2.14$ \\
\hline
\end{tabular}

Interpretation: Atotal of two participants discontinued the intervention due to medical reasons, reflecting a $5.7 \%$ attrition rate. The majority of students were female $(90 \%)$ and did not vaccinate $(85 \%)$. None of the students had any kind of hepatitis. The students' average grade of the infection prevention and control course was 7.85 \pm 2.14 points and the scores ranged from 5.00 to 9.50 points. 
Table 3. Comparisons of outcome variables at three-time measures by using t-test

\begin{tabular}{|lccccc|}
\hline \multicolumn{1}{|c}{ Variables } & Week & \multicolumn{2}{c}{$\mathrm{n}=33$} & $\mathbf{t}$ & $\mathbf{p}$ \\
& & Mean & SD & & \\
\hline \multirow{3}{*}{ Knowledge } & 0 & 6,05 & 2,12 & $\mathrm{t}_{1-2}=28,72$ & $\mathrm{p}_{1-2}<0,001$ \\
& 4 & 7,14 & 2,15 & $\mathrm{t}_{1-3}=21,11$ & $\mathrm{p}_{1-3}<0,001$ \\
& 8 & 7,47 & 3,05 & $\mathrm{t}_{2-3}=19,60$ & $\mathrm{p}_{2-3}>0,05$ \\
\hline \multirow{2}{*}{ Attitude } & 0 & 82,57 & 22,56 & $\mathrm{t}_{1-2}=37,71$ & $\mathrm{p}_{1-2}<0,001$ \\
& 4 & 90,97 & 18,05 & $\mathrm{t}_{1-3}=22,94$ & $\mathrm{p}_{1-3}<0,001$ \\
& 8 & 86,52 & 20,16 & $\mathrm{t}_{2-3}=11,98$ & $\mathrm{p}_{2-3}>0,05$ \\
\hline \multirow{3}{*}{ Self-reported behavior } & 0 & 14,35 & 4,08 & $\mathrm{t}_{1-2}=15,21$ & $\mathrm{p}_{1-2}<0,001$ \\
& 4 & 20,19 & 3,86 & $\mathrm{t}_{1-3}=31,04$ & $\mathrm{p}_{1-3}<0,001$ \\
& 8 & 18,42 & 4,01 & $\mathrm{t}_{2-3}=19,28$ & $\mathrm{p}_{2-3}>0,05$ \\
\hline
\end{tabular}

Interpretation: All the total scores of knowledge, attitude and self-reported behavior of exposure prevention among students were measured at the three-time points of; before beginning the intervention (T1), after the intervention at week 2 (T2), and at the follow-up at week 4 (T3). Table 3 presents the descriptive statistics; the differences of the total scores of knowledge, attitude and self-reported behavior of exposure prevention among students between the three-time points. The $t$-test results showed that there were improvements for the participants after participating in the case-based educational intervention.

Table 4. Paired comparision at each time point

\begin{tabular}{|ccc|}
\hline Time & $\mathbf{M}_{\text {diff }}$ & p-value \\
\hline$T_{1}$ vs. $T_{2}$ & $-1,09$ & $<0,001$ \\
$T_{1}$ vs. $T_{3}$ & $-1,42$ & $<0,001$ \\
$T_{2}$ vs. $T_{3}$ & $-0,33$ & $>0,05$ \\
\hline$T_{1}$ vs. $T_{2}$ & $-8,40$ & $<0,001$ \\
$T_{1}$ vs. $T_{3}$ & $-3,95$ & $<0,001$ \\
$T_{2}$ vs. $T_{3}$ & 4,45 & $>0,05$ \\
\hline$T_{1}$ vs. $T_{2}$ & $-5,84$ & $<0,001$ \\
$T_{1}$ vs. $T_{3}$ & $-4,07$ & $<0,001$ \\
$T_{2}$ vs. $T_{3}$ & 1,77 & $>0,05$ \\
\hline
\end{tabular}


Interpretation: Moreover, the results of the pairwise comparisons were conducted to determine the differences between pairs of time measurements for knowledge, attitude and self-reported behavior scores. There were significant differences in knowledge, attitude and self-reported behavior scores in at least one pair of the three-time points, $(p<0.001)$. The findings indicated that participants after receiving the case-based educational intervention had better knowledge, attitude and selfreported behavior of exposure prevention than pre-intervention. Details are in Table 4.

\section{DISCUSSION}

The main purpose of the current study was to develop and determine the feasibility of the case-based educational intervention and at the same time examine the initial effectiveness of the intervention to obtain initial signals of improvement in the knowledge, attitude and self-reported behavior of exposure prevention among nursing students. The result showed that the case-based educational intervention program, which combined educational sessions and designed cases, found a significant difference in the mean score of knowledge, attitude and self-reported behavior across three-point times. The feasibility study showed that nursing students and faculty in Nam Dinh University of Nursing can understand and apply the case-based educational interventions that improve knowledge, attitude and selfreported behavior of exposure prevention among nursing students. Through literature review and observation, this was one of the very popular intervention studies on the students. Especially, the intervention program supported students both problemsolving skills and action plan skills.
The results of our study were similar to a few previous studies that were performed on students [10-14]. In a 2015 study evaluating the effectiveness of a needle and sharps injury prevention intervention program during clinical training of nursing students. The intervention program follows a multimodal approach that includes a combination of videos, PowerPoint presentations, and hands-on demonstrations to help students apply and practice infection prevention and control. The program significantly improved nursing students' knowledge and practice on infection prevention, and it is suggested that such sessions should be incorporated into the curriculum [12].

One study that applied the intervention program indicated that both groups demonstrated a statistically significant increase in knowledge and awareness of standard precautions and infection control after the intervention. The results of this study contributed to the evidence regarding effective educational methods for improving infection control [13]. During the intervention program, students were given a discussion of clinical cases related to the prevention of exposure to blood and fluid in nursing practice, moreover, the students had the opportunity to develop and implement behavior improvement following individual action plans. That was the key component in improving student knowledge, attitudes and behavior. Previous research recommended that the intervention should be regularly reinforced with individual weekly action plans to help maintain the safe practice for the prevention of blood and body fluids exposure [14].

Similar interventions were applied with the longer intervention time and followshowed better behavioral improvement 
compared to the present study. In this study, at 3 months after the intervention, the mean behavioral score in the intervention group was significantly higher than that of the control group and much higher than before the intervention [12]. The difference was explained by the fact that, in their study, in addition to presentations and group discussions, they also applied both direct practical instruction and a 2-month intervention period. Therefore, behavior improved markedly and was maintained after intervention for up to 3 months. Moreover, Le Thi Anh Thu (2010) applied a program to strengthen infection control to limit occupational exposure, including training to raise awareness of health workers, providing adequate enough protective equipment and means to improve hepatitis $B$ vaccination for health workers. After applying for the program, the exposure rate decreased significantly. Frequent retraining was associated with year-on-year declines. The psychology of medical staff was more stable after an occupational accident. The illegal mass HIV testing decreased markedly [9].

This study has certain limitations. First, the 1-month follow-up period was relatively short, so the long-term effects of exposure prevention needed further investigation. Secondly, students provided feedback on their exposure prevention behavior by self-reported forms, rather than being directly observed by the team in clinical practice, reducing their ability to detect discrepancies in study outcomes. Thirdly, the study was only conducted on a group of students without a control group, there may be different reporting biases, whereas nursing students participating in the casebased educational intervention may be more likely to report exposure prevention attitudes and behaviors better compared to the usual. Finally, the cases were developed by the research group, who were lecturers with a background in nursing. Future research should consider multidisciplinary involvement in the design of clinical cases.

\section{CONCLUSION}

The results from the study suggested that a case-based educational intervention can be used effectively for nursing students. The group discussion sessions based on action plans focusing on problemsolving strategies helped nursing students in improving the knowledge, attitude and behavior of exposure prevention. The intervention was feasible when faculty, as well as clinical instructors, understand and practice providing to the students in the clinical settings.

\section{REFERENCES}

1. Ministry of Health. (2012a). Guidelines for safe injections in medical examination and treatment establishments. Issued together with Decision No. 3671/ QD-BYT of the Minister of Health approving the Infection Control Guidelines.

2. Ministry of Health. (2012b). Training materials for infection prevention and control. Hanoi: Medical Publishing House.

3. CDC. (2001). Guidelines for the Management of Occupational Exposures to $\mathrm{HBV}, \mathrm{HCV}$, and HIV and Recommendations for Postexposure Prophylaxis. MMWR Recomm Rep, 50(Rr-11), 1-52.

4. Cooke, J., Greenway, K., \& Schutz, S. (2021). Learning from nursing students' experiences and perceptions of their clinical placements in nursing homes: 
An integrative literature review. Nurse Education Today, 100, 104857. https://doi. org/10.1016/j.nedt.2021.104857

5. Ören, B., \& Zengin, N. (2019). Assessing Health Threatening Problems among Nursing or Midwifery Students during the Clinical Education Course in Turkey. Iranian Journal Of Public Health, 48(1), 85-94.

6. V. Hada et al. (2018). Nursing students: A vulnerable health-care worker for needlesticks injuries in teaching hospitals. J Family Med Prim Care. 7(4) 717-720.

7. Hada, V., Saurabh, K., Sharma, A., Nag, V. L., Gadepalli, R. S., \& Maurya, A. K. (2018). Nursing students: A vulnerable health-care worker for needlesticks injuries in teaching hospitals. Journal Of Family Medicine And Primary Care, 7(4), 717-720. https://doi.org/10.4103/jfmpc. ifmpc 265 17

8. Markovic-Denic, L., Maksimovic, N., Marusic, V., Vucicevic, J., Ostric, I., \& Djuric, D. (2015). Occupational exposure to blood and body fluids among health-care workers in Serbia. Medical Principles and Practice: International Journal of the Kuwait University, Health Science Centre, 24(1), 36-41. https://doi.org/10.1159/000368234

9. H. Handiyani et al. (2018), The effective needle stick injury prevention strategies for nursing students in the clinical settings: a literature review. Enferm Clin. 28 (1),167-171. doi:10.1016/S11308621(18)30060-3

10. Kim, E., Kim, S. S., \& Kim, S. (2020). Effects of Infection Control Education for Nursing Students Using Standardized Patients vs. Peer Role-Play. International Journal Of Environmental Research And
Public Health, 18(1), 107. https://doi. org/10.3390/ijerph18010107

11. Kim, J., Park, J. H., \& Shin, S. (2016).

Effectiveness of simulation-based nursing education depending on fidelity: a metaanalysis. BMC medical education, 16, 152. https://doi.org/10.1186/s12909-016-0672-7

12. Dieckmann, P., Torgeirsen, K., Qvindesland, S. A., Thomas, L., Bushell, V., \& Langli Ersdal, H. (2020). The use of simulation to prepare and improve responses to infectious disease outbreaks like COVID-19: practical tips and resources from Norway, Denmark, and the UK. Advances in simulation (London, England), 5, 3. https://doi.org/10.1186/ s41077-020-00121-5

13. Wu, C. J., Gardner, G., \& Chang, A. M. (2009). Nursing students' knowledge and practice of infection control precautions: an educational intervention. Journal Of Advanced Nursing, 65(10), 21422149 . $\quad$ https://doi.org/10.1111/j.13652648.2009.05079.x

14. Desnita, et al. (2020). Peer-Assisted Learning in Nursing Student Knowledge and Compliance in the Application of Standard Precautions. Jurnal Keperawatan Indonesia, 23 (3), 162-169. DOI: 10.7454/ jki.v23i3.1233 